\title{
Ion transport in hydrated compounds based on crystalline polyantimonic acid
}

\author{
(C) Vladimir A. Burmistrov, ${ }^{1}$ Lilia Yu. Kovalenko, ${ }^{1}$ Olga A. Firsova, ${ }^{2}$ \\ Elena M. Filonenko, ${ }^{2}$ and Yulia A. Lupitskaya ${ }^{2 *^{+}}$ \\ ${ }^{1}$ Department of Solid State Chemistry and Nanoprocesses. Chelyabinsk State University. \\ Molodogvardeitsev St., 70-B. Chelyabinsk, 454021. Russia. \\ Phone:+7 (351) 799-70-63. E-mail: burmistrov@csu.ru \\ ${ }^{2}$ Department of Condensed Matter Physics. Chelyabinsk State University.Bratiev Kashirinyh St., 129. \\ Chelyabinsk, 454001. Russia. Phone: +7 908-056-32-92. E-mail: lupitskaya@gmail.com
}

\begin{abstract}
*Supervising author; ${ }^{+}$Corresponding author
Keywords: crystalline polyantimonic acid, ion-substituted forms, pyrochlore-type structure, ion and proton transport.
\end{abstract}

\begin{abstract}
The present work is devoted to the study of crystalline polyantimonic acid (CPA) structural properties in conditions of ion exchange and heat treatment of its substituted $\mathrm{Ag}^{+}, \mathrm{H}^{+}$-forms. According to the obtained data of X-ray diffraction qualitative phase analysis, the compounds analyzed crystallize within the framework of the pyrochlore type structure (space group $F d-3 m$ ). For phases being isomorphic to this structural type, it was shown that with an increase in the degree of substitution $\alpha$, a relative intensity redistribution of the group of reflections with even and odd indices and decrease of unit cell parameter $a$ were observed.. The data of thermogravimetric analysis allows to conclude that the thermolysis of CPA's ion-substituted forms proceeds in a wide temperature range from 297 to $973 \mathrm{~K}$ being accompanied by a decrease of samples weight. Applying the Rietveld method, the structural characteristics of CPA and its derivatives were refined, and a model of populating the corresponding metal ions by crystallographic positions within a pyrochlore-type structure was proposed. Using a complex of physicochemical methods (thermogravimetric and X-ray diffraction analyses), the effect of hydration of CPA compounds with a pyrochlore type structure on transport properties was determined. It is shown that with an increase of substitution degree $\alpha$ in samples of CPA's $\mathrm{Ag}^{+}, \mathrm{H}^{+}$-forms in conditions of alternating current the value of the specific conductivity decreases monotonically. An increase of silver ions content in the phases of $\mathrm{Ag}^{+}, \mathrm{H}^{+}$-forms leads to the change of proton-binding energy with the crystal lattice. In the condition of elevated temperature in hydrated CPA compounds, charge transfer is performed by silver ions. It was found that the electrical conductivity in the samples analyzed can also rise with a silver ions amount decrease (16d-positions are partially filled with $\left.\mathrm{Sb}^{3+}\right)$.
\end{abstract}

\section{References}

[1] A.B. Yaroslavtsev, Yu.A. Dobrovolsky, N.S. Shaglaeva, L.A. Frolova, E.V. Gerasimova, E.A. Sanginov. Nanostructured materials for low-temperature fuel cells. Russ. Chem. Rev. 2012. Vol.81. No.3. P.191220. (russian)

[2] Yu.A. Lupitskaya, V.A. Burmistrov. Ionic conductivity of potassium antimonite tungstates with partal $\mathrm{Na}^{+}$or $\mathrm{Li}^{+}$substitution for $\mathrm{K}^{+}$. Inorganic Materials. 2013. Vol.49. No.9. P.998-1002. (russian)

[3] O.A. Mezhenina, V.A. Burmistrov, A.A. Biryukova. Structure and ion-exchange properties of crystalline tungstoantimonic acid. Inorganic Materials. 2015. Vol.51. No.2. P.167-171.

[4] I.A. Stenina, A.B. Yaroslavtsev. Low- and intermediate-temperature proton-conducting electrolytes. Inorganic Materials. 2017. Vol.53. No.3. P.241-251. (russian)

[5] L.Yu. Kovalenko, V.A. Burmistrov, Yu.A. Lupitskaya, I.N. Kovalev, and D.M. Galimov. Synthesis of the solid solutions $\mathrm{H}_{2} \mathrm{Sb}_{2-\mathrm{x}} \mathrm{V}_{\mathrm{x}} \mathrm{O}_{6} \cdot \mathrm{nH}_{2} \mathrm{O}$ with the pyrochlore-type structure. Butlerov Communications. 2018. Vol.55. No.8. P.24-30. DOI: 10.37952/ROI-jbc-01/18-55-8-24

[6] L.Yu. Kovalenko, F.A. Yaroshenko, V.A. Burmistrov, T.N. Isaeva, D. M. Galimov. Thermolysis of Hydrated Antimony Pentoxide. Inorganic Materials. 2019. Vol.55. No.6. P.586-592. 